\title{
Evaluation of meteorological drought using the Standardized Precipitation Index (SPI) in the High Ziz River basin, Morocco
}

\author{
Khadija Diani $^{{ }^{*}}$, Ilias Kacimi ${ }^{1}$, Mahmoud Zemzami ${ }^{2}$, Hassan Tabyaoui ${ }^{3}$, Ali Torabi Haghighi ${ }^{4}$ \\ ${ }^{1}$ LGEE Laboratory, Department of Earth Sciences, Faculty of Sciences, Mohammed V-Agdal University, Rabat, Morocco, \\ e-mail: diani.khadija@gmail.com ( ${ }^{*}$ corresponding author) \\ ${ }^{2}$ Ministry Delegate to the Minister of Energy, Mines, Water and Environment, in charge of water, Rabat, Morocco \\ ${ }^{3}$ Natural Resources and Environment Laboratory, Polydisciplinary Faculty of Taza, Sidi Mohamed Ben Abdullah University, Fez, Morocco \\ ${ }^{4}$ Water, Energy and Environmental Engineering Research Unit, University of Oulu, PO Box 4300, FIN-90014, Finland
}

\begin{abstract}
One of the adverse impacts of climate change is drought, and the complex nature of droughts makes them one of the most important climate hazards. Drought indices are generally used as a tool for monitoring changes in meteorological, hydrological, agricultural and economic conditions. In this study, we focused on meteorological drought events in the High Ziz river Basin, central High Atlas, Morocco. The application of drought index analysis is useful for drought assessment and to consider methods of adaptation and mitigation to deal with climate change. In order to analyze drought in the study area, we used two different approaches for addressing the change in climate and particularly in precipitation, i) to assess the climate variability and change over the year, and ii) to assess the change within the year timescale (monthly, seasonally and annually) from 1971 to 2017. In first approach, precipitation data were used in a long time scale e.g. annual and more than one-year period. For this purpose, the Standardized Precipitation Index (SPI) was considered to quantify the rainfall deficit for multiple timescales. For the second approach, trend analysis (using the Mann-Kendall (M-K) test) was applied to precipitation in different time scales within the year. The results showed that the study area has no significant trend in annual rainfall, but in terms of seasonal rainfall, the magnitude of rainfall during summer revealed a positive significant trend in three stations. A significant negative and positive trend in monthly rainfall was observed only in April and August, respectively.
\end{abstract}

Key words: climate change, rainfall, multiple timescales, Mann-Kendall test

\section{Introduction}

Drought is a natural hazard characterized as having below normal precipitation as a result of numerous variables acting on multiple time scales (months to years) and it can vary spatially, thus, drought can have impacts on various sectors, especially on hydrological conditions, agriculture and ecosystems (Homdee et al. 2016). Drought analysis can gather information which can serve as the basis for integrated water resources management under climate variability/change conditions especially on the basin scale (Stagge et al. 2015; Huang et al. 2015; Oloruntade et al. 2017). Issues of climate variability/change have been a concern for scientists and policymakers for decades because of their immediate and long-lasting environmental consequences. The conclusions of analyses made on climate change by the Intergovernmental Panel on Climate Change (IPCC 2000, 2007) have shown a change in the energy balance of the "Earth-Ocean-Atmosphere-Biosphere" system. Drought has continued to be one of the most threatening natural hazards in the present century $(\mathrm{Ol}-$ iveira-Júnior et al. 2018), and is likely to develop more rapidly than the mean climate under global warming (Dai et al. 2004). Meteorological drought is a climatic phenomenon rather than a hazard itself, but it is often confused with other climatic conditions to which it is related, particularly aridity. It becomes hazardous when it transforms to agricultural or hydrological drought, which depends on other factors than the lack of rainfall alone. In such a case it has adverse effects on all sectors depending on water resources (Lin et al. 2007; Mishra and Singh 2010; Darabi et al. 2017; Haghighi et al. 2018; Ashraf et al. 2018). The spatial extent of drought is generally much greater than other natural disasters, the impacts are generally non-structural and difficult to quantify. Compared with other hydrological hazards, such as floods, the development of droughts is slow and it is 
very difficult to identify the moment at which droughts start and finish (Burton et al. 1978).Thus, drought is probably the best example of a "penetrating" natural hazard. In general, droughts are recognized only when human activities and the environment are affected (Vicente-Serrano and López-Moreno 2005; Haghighi et al. 2018).

The purpose of this study is to investigate precipitation variability and its trend over the Ziz River basin, which is located in the central high Atlas in southeastern Morocco, between 197 and 2017. The variability of precipitation has been principally established on the basis of the calculation of the standardized precipitation index (SPI), developed by McKee et al. (1993) which indicates the severe and lasting nature of the drought in this catchment, and the results could help policymakers to target intervention strategies, adapt agricultural and pastoral projects to climate change and consequently reduce the impact of drought periods. The precipitation trend analysis has been conducted using the MannKendall (M-K) test.

\section{Study area}

The study was carried out in the upper part of the Ziz River basin, which is located in the central high Atlas, in south-eastern Morocco (Fig. 1). It extends from the east of the central high Atlas to the western part of the eastern high Atlas. It is limited in the north by upper Moulouya (Eastern Meseta), in the south by the eastern Anti-Atlas. It contains superficial and deep layers.

The area of Ziz River basin is $4001.3 \mathrm{~km}^{2}$. It is a mountainous area with a wide range of variation in altitudes (from 3499 m a.s.l. in the Zaouiat Sidi Hamza to less than 1149 m a.s.l. in the Outlet of Foum Zaabel), complex topography, dominated by steep slopes. Relief and lithology are illustrated in (Fig. 2), which shows that the high Ziz basin consists essentially of dolomite, limestone, calcareous marl alternations, and silico-clastic detritus (Igmoullan et al. 2001). The Ziz river flows north-south across a Paleozoic area (limestone, shale and clays), the Inner Sierras (limestone and sandstones) and the Flysch sector, it then arrives at the Inner depression (marls), and runs northward until the outlet of Foum Zaabel.

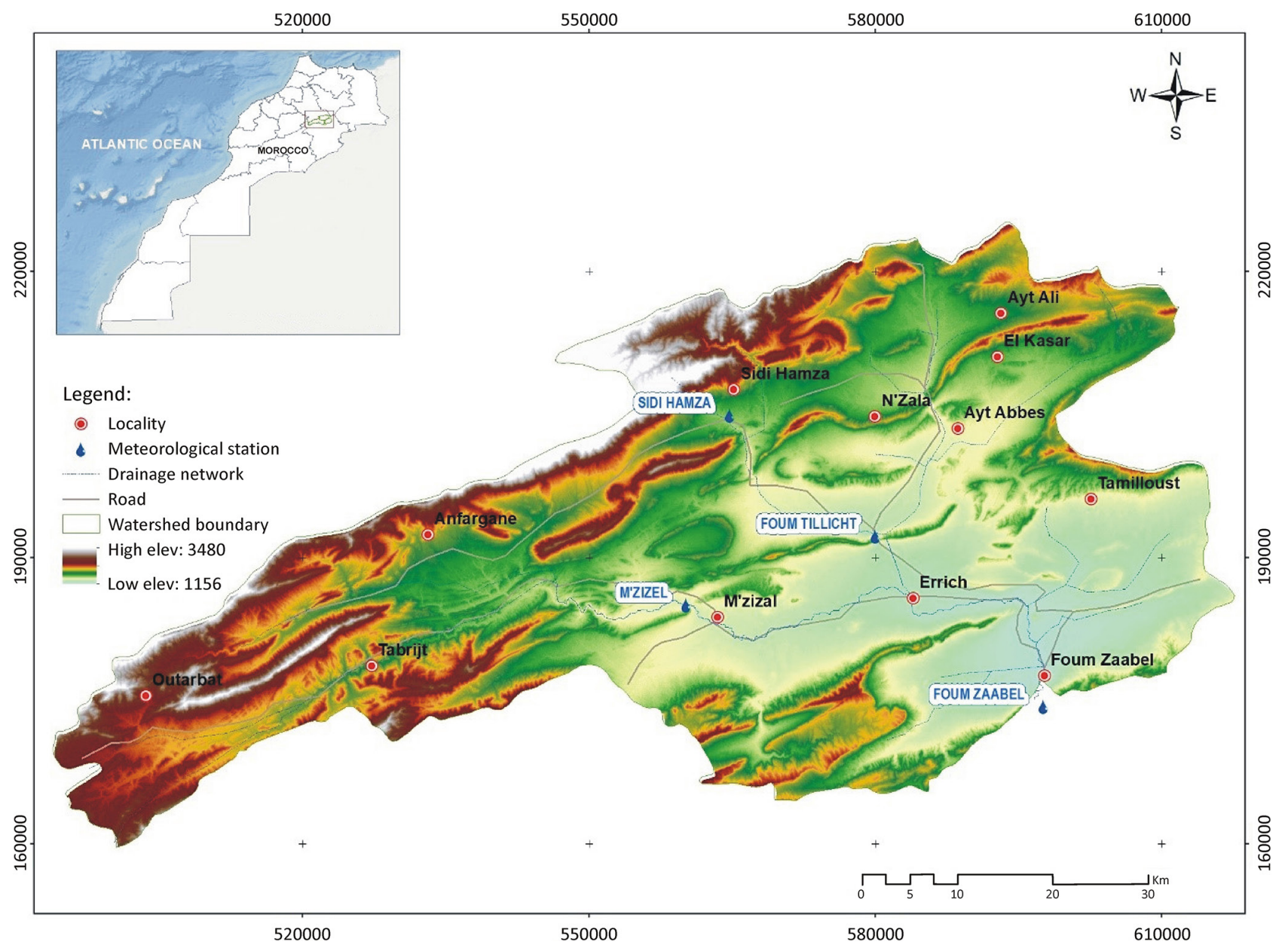

Fig. 1. Location of High Ziz River basin, southeast Morocco 


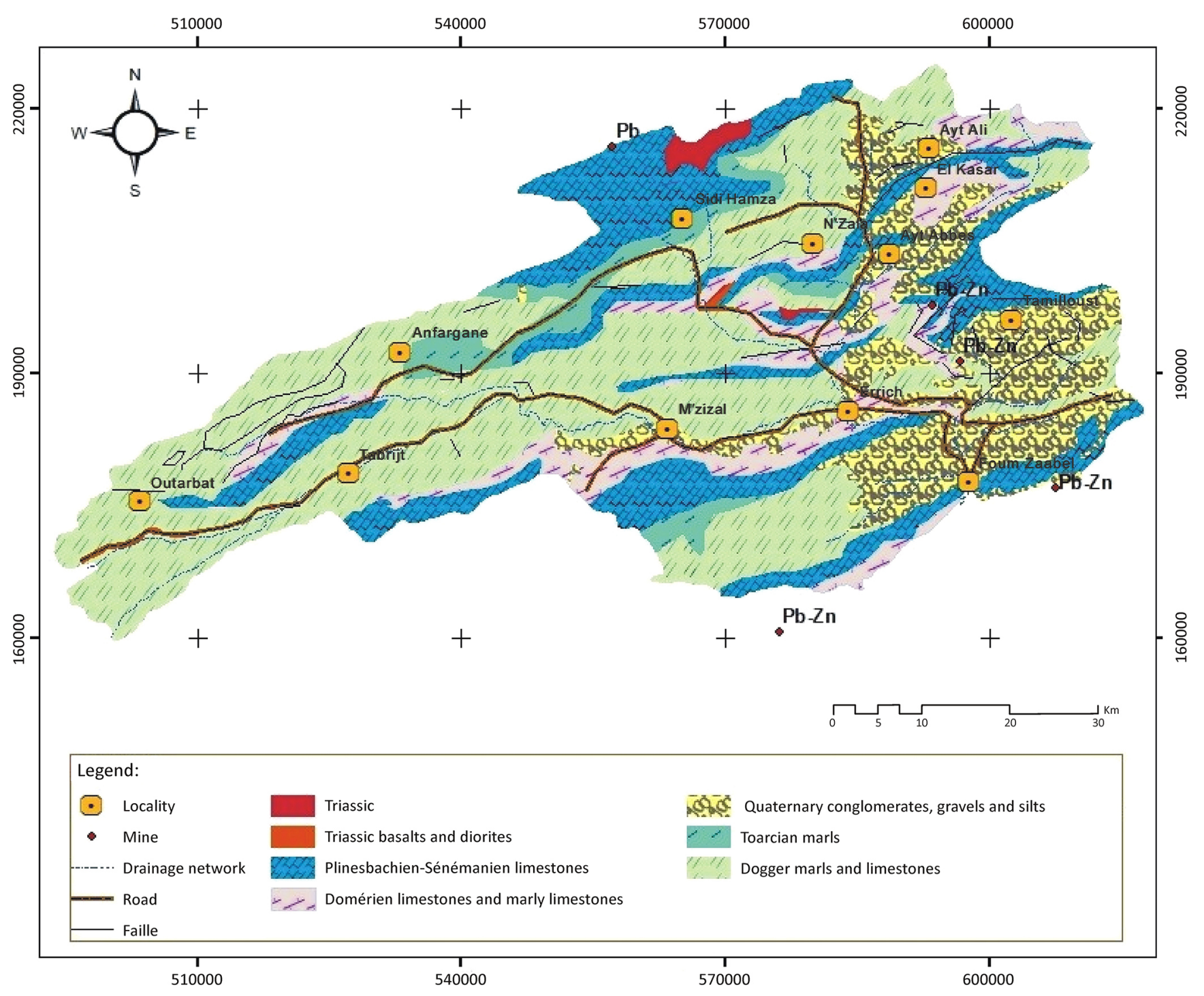

Fig. 2. Lithology of High Ziz River basin

\section{Methods}

In this study, by considering the level and duration of drought and the trend of precipitation in different time scales, we tried to address the climate variability and change over the study area. In order to analyze the drought and variability of precipitation, we used two different approaches for addressing the change in climate and particularly in precipitation, assess the climate variability and change over the years and within the year timescale (monthly, seasonally and annually) in the period 1971 to 2017 . The monthly precipitation data from four metrological stations were used in the analysis (Table 1).

In the first approach, precipitation data were used in a longer time scale, annual and more than one-year period, for this reason change in Standardized Precipitation Index (SPI) was considered to quantify the rainfall deficit for multiple timescales as 12, 36, 60 and 120 months. In the second approach, trend analysis was applied for precipitation in different short-time scales within a year by using the Mann-Kendall (M-K) test e.g. monthly, quarterly, semester and annual trends. The two methods, SPI and M-K are explained as follows.

\section{Standardized Precipitation Index (SPI)}

The Standardized Precipitation Index (SPI) was used to illustrate meteorological drought, which is caused by a deficiency of precipitation. It was developed by McKee et al. (1993). The SPI is an index based on the probability of precipitation for any time scale. In McKee et al. (1993), SPI was calculated at, 6, 12, 24, 36, and 48-month time scales based on Fort Collins, Colorado data. Then long-term precipitation data were fitted into a probability distribution, after which they were trans- 
Table 1. Geographical location of the metrological stations in the high Ziz River basin and basic characteristics of monthly rainfall

\begin{tabular}{|l|c|c|c|c|}
\hline \multirow{2}{*}{\multicolumn{1}{c|}{ Parameters }} & \multicolumn{4}{c|}{ Meteorological station } \\
\cline { 2 - 5 } & Zaouiat Sidi Hamza & M'Zizel & Foum Tillicht & Foum Zaabel \\
\hline Longitude X & 564215 & 560000 & 579850 & 1797450 \\
\hline Latitude Y & 204361 & 185300 & 192500 & 1253 \\
\hline Altitude [m a.s.I.] & 1738 & 1600 & 1627 & $46(1971-2016)$ \\
\hline Time span & $48(1971-2017)$ & $48(1971-2017)$ & $43(1976-2017)$ & 68.4 \\
\hline Minimum [mm] & 42.7 & 65.8 & 25.6 & 406.7 \\
\hline Maximum [mm] & 575.1 & 404.8 & 471.6 & 183.44 \\
\hline Average [mm] & 264.80 & 184.34 & 197.61 & 171.8 \\
\hline Median [mm] & 241.85 & 162.05 & 95.91 & 82.15 \\
\hline Standard Deviation & 98.95 & 84.53 & 48.53 & 44.78 \\
\hline Variation [\%] & 37.36 & 45.85 & & \\
\hline
\end{tabular}

formed into a standard distribution. Thus, the region specific deviation from the data is largely eliminated. Zero denotes normal conditions, while positive and negative values indicate wet and dry conditions. The SPI index can provide early warnings to help assess drought severity. However, it is only derived from the meteorological element of precipitation without considering other important parameters for the description of drought, such as evapotranspiration or soil moisture. Therefore, a more comprehensive index should also be used to serve as a comparison.

To calculate the SPI index at a specific location, the precipitation record for a long-term period is collected and this data is fitted to a probability distribution and then converted into a normal distribution. Estimating the SPI involves describing the frequency distribution of precipitation using a gamma probability density function:

$$
\mathrm{P}(x)=\frac{1}{\beta^{\alpha} \Gamma(\alpha)} x^{\alpha-1} e^{-x / \beta}, x>0
$$

where: $x$ is the precipitation amount, $\alpha$ is the shape parameter, $\beta$ is the scale parameter and the gamma function is expressed as:

$$
\Gamma(\alpha)=\int_{0}^{\infty} x^{\alpha-1} e^{-x} d x
$$

The maximum likelihood method is used to estimate the optimal values of $\alpha$ and $\beta$ (Thom 1966):

$$
\begin{gathered}
\hat{\alpha}=\frac{1}{4 A}\left(1+\sqrt{1+\frac{4 A}{3}}\right), \\
\hat{\beta}=\frac{\bar{x}}{\hat{\alpha}}, \\
A=\ln (\bar{x})-\frac{\Sigma \ln (x)}{n},
\end{gathered}
$$

where: $n$ is the number of precipitation records, and $x$ is the amount of average precipitation. The cumulative probability for a given month can then be obtained by applying the following equation:

$$
G=\int_{0}^{x} g(x) d x=\frac{1}{\hat{\beta}^{\hat{\alpha}} \Gamma(\hat{\alpha})} \int_{0}^{x} x^{\hat{\alpha}-1} e^{-x / \hat{\beta}} d x .
$$

Setting $\mathrm{t}=x / \beta^{\wedge}$, the incomplete gamma function can be obtained:

$$
G(x)=\frac{1}{\Gamma(\hat{\alpha})} \int_{0}^{x} t^{\hat{\alpha}-1} e^{-t} d t .
$$

It is possible to have several zero values in a sample set. In order to account for the zero value, because the gamma distribution is undefined for $x=0$, the cumulative probability function for gamma distribution is modified as:

$$
H=q=(1-q) G(x),
$$

where: $q$ and $(1-q)$ denote the probabilities of zero and non-zero precipitations, respectively. The SPI is then derived from the cumulative probability, as follows:

$$
S P I=\left(\begin{array}{c}
\frac{(c 2 k+c 1) k+c 0}{((d 3 k+d 2) k+d 1) k+1.0}, \\
k=\sqrt{\ln \left(\frac{1}{(1-H(x))^{2}}\right), 0.5<H(x)} \\
-\left(k-\frac{(c 2 k-c 1) k+c 0}{((d 3 k+d 2) k+d 1) k+1.0}\right), \\
k=\sqrt{\ln \left(\frac{1}{H(x)^{2}}, 0<H(x) \leq 0.5\right.}
\end{array}\right),
$$


Table 2. SPI classification according to McKee et al. (1993)

\begin{tabular}{|c|c|}
\hline Range of SPI & Description of state \\
\hline $\mathrm{SPI} \geq 2.0$ & Extremely wet $(\mathrm{EW})$ \\
\hline $1.5 \leq \mathrm{SPI}<2.0$ & Severely wet $(\mathrm{SW})$ \\
\hline $1.0 \leq \mathrm{SPI}<1.5$ & Moderately wet $(\mathrm{MW})$ \\
\hline $0 \leq \mathrm{SPI}<1.0$ & Normally wet (NW) \\
\hline$-1.0 \leq \mathrm{SPI}<0$ & Normally dry (ND) \\
\hline$-1.5 \leq \mathrm{SPI}<-1.0$ & Moderately dry (MD) \\
\hline$-2.0 \leq \mathrm{SPI}<-1.5$ & Severely dry (SD) \\
\hline $\mathrm{SPI}<-2.0$ & Extremely dry (ED) \\
\hline
\end{tabular}

et al. 2002). Table 2 shows the categorization of drought and wet, classified based on the SPI (McKee et al. 1993).

\section{Trend analysis}

The non-parametric Mann-Kendall test (Gilbert 1987; Kendall 1948; Mann 1945) has generally been used to determine the significance of a trend at a site (Pirnia et al. 2018). This test is based on the statistic S:

$\mathrm{S}=\sum_{\mathrm{k}=0}^{\mathrm{n}-1} \sum_{\mathrm{j}=\mathrm{k}+1}^{\mathrm{n}} \operatorname{sgn}\left(\mathrm{x}_{\mathrm{j}}-\mathrm{x}_{\mathrm{k}}\right) \quad \operatorname{sgn}(\mathrm{x})=\left\{\begin{array}{l}+1, \mathrm{x}>0 \\ 0, \mathrm{x}=0 \\ -1, \mathrm{x}<0\end{array}, \quad[10]\right.$

where: $\mathrm{n}$ is the length of the data and $x_{j}$ and $x_{k}$ are the data values in a time series $k$ and $j(j>k)$, respectively. In cases where the sample size $n \geq 10$, the mean and variance are given by:

$$
\mathrm{E}(\mathrm{s})=0 .
$$

$\operatorname{Var}(\mathrm{s})=\sigma_{\mathrm{s}} \sqrt{\left\{\mathrm{n}(\mathrm{n}-1)(2 \mathrm{n}+5)-\Sigma_{1}^{\mathrm{r}} \mathrm{t}_{\mathrm{i}}\left(\mathrm{t}_{\mathrm{i}}-1\right)\left(2 \mathrm{t}_{\mathrm{i}}+5\right)\right\} / 18 .}[12$

In Equation (12), $\mathrm{n}$ is the number of tied groups and ti denotes the number of ties of extent $i$. A tied group is a set of sample data having the same value. The standard normal test statistic $\mathrm{Z}$ is computed as:

$$
Z=\left\{\begin{array}{cc}
\frac{S-1}{\sqrt{\operatorname{Var}(S)}} & S>0 \\
0 & S=0 \\
\frac{S+1}{\sqrt{\operatorname{Var}(S)}} & S<0
\end{array} .\right.
$$

According to Equation 13 positive values of $\mathrm{Z}$ show increasing trends while a negative $\mathrm{Z}$ indicates decreasing trends. The testing of trends is made at a specific significance level $\alpha$. The significance level $\alpha=0.05$ was used in this study. At the 5\% significance level, the null hypothesis of no trend is rejected if $|\mathrm{Z}|>1.96$ (Mann
1945; Kendall 1975; Darabi et al. 2019). The trend analysis was done for monthly, quarterly and semesterly (6 months) rainfall. For monthly analysis we calculated the trend for each month separately. For quarterly and semesterly rainfall analysis we produced a time series of three and six months rainfall then we evaluated the trend. For example for quarterly, the summing up of three continuous months' rainfall were calculated, e.g. January to March (JFM), February to April (FMA), and December to February (DJF); we then evaluated the trend for each three continuous months separately. Finally there are 37 items (12 monthly, 12 quarterlies, 12 semesterly and an annual) for trend analysis. The result for each item was categorised as a positive $(Z>0)$ and negative $(Z<0)$ trend $(\alpha \leq 0.05)$ or a positive $(Z>0)$ and negative $(Z<0)$ tendency $(\alpha>0.05)$.

\section{Results}

\section{Analysis of SPI and characteristics of drought}

The overall results of four stations revealed a clear cyclic pattern of wet and dry period conditions (Fig. 3 and Table 3). Long-term variability of precipitation over the regions showed in clear contrast to a dry period which began in the late nineteen seventies and a wet period which was observed from late nineteen nineties (Fig 3 and Table 3). For all stations the wettest decade and other periods e.g. 12 months (annual), 36 months ( 3 years) and 60 months ( 5 years) were observed after 2002 (Table 3 and Fig. 3). The driest decade for Zaouiat Sidi Hamza, M'Zizel and Foum Tillicht began in 1977/02, 1976/10 and 1978/01 respectively (all in late nineteen-seventies) while for Foum Zaabel it began in 1996/09 (Table 3 and Fig. 3).

The results of the SPI analysis at the Zaouiat Sidi Hamza station revealed that the driest and wettest 12 months started from Dec-1983 (which indicate extreme drought, the SPI was 2.0) and Nov-2014 (which indicate extreme wet, the SPI was +2.74) (Fig. 3 and Table 3). Further, all long-term wettest periods including three, five and ten years started from 2006 while the driest periods began in 1981, 1979 and 1977 respectively (Table 3 ). There is a remarkable dominance of dry and wet periods (1971-1985) and (1998-2015).

For the M'Zizel station the result shows a dominance of dry and wet periods during (1971-1985) and (2002-2015) respectively (Fig. 3 ). In addition, the wettest 12 months started from Jan-2008 while the driest year was observed from Mar-1981 to Feb-1982 (Fig. 3 and Table 3). Further long-term wet periods began in 2006, 2006 and 2005 for periods of three, five and ten years while other dry periods started in 1998, 1997 and 1976 respectively (Table 3). At the Foum Zaabel station the results confirm alternating dry and wet peri- 

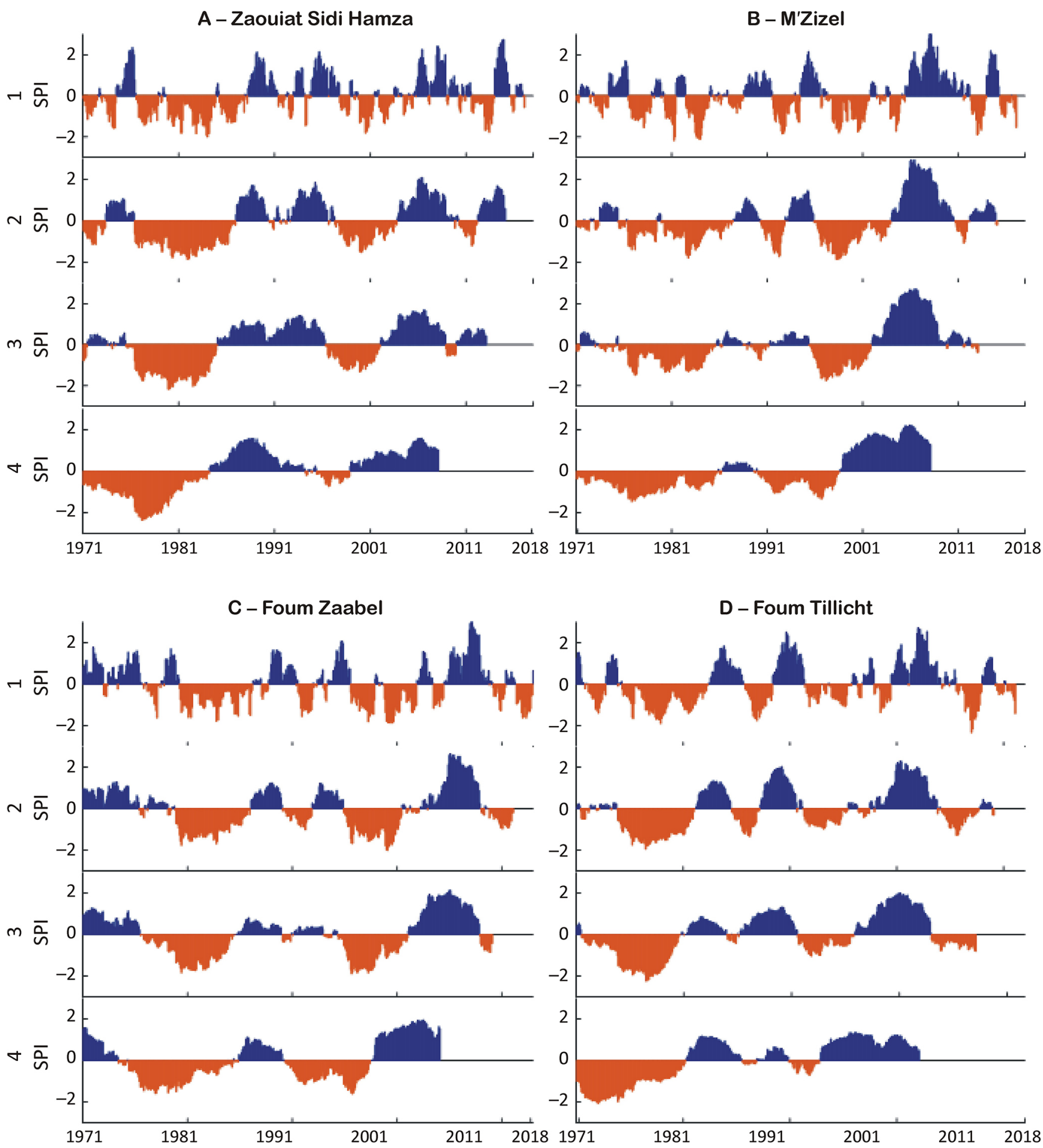

Fig. 3. Variation of SPI in different periods for the Zaouiat Sidi Hamza (A) M'Zizel (B), Foum Zaabel (C) and Foum Tillicht (D) stations. 1, 2, 3 and 4 indicate different period of analysis as 12, 36, 60, 120 months respectively

ods (Fig. 3). The wettest and driest years began from Feb-2008 and Jun-2000 (Table 3). Long-term droughts at this station began from 2000, 1996 and 1996 for 3, 5 and 10 years periods respectively (Table 3 and Fig. 3). At the Foum Tillicht Station, the SPI analysis indicates that the periods of maximum SPI value for wet conditions began in 2007, 2006, 2006 and 2002 for 1, 3, 5 and 10 years while drought periods started from 2012, 1982, 1982 and 1978 respectively. 
Table 3. Wettest and driest periods based on SPI value at different stations (category for SPI according to Table 2)

\begin{tabular}{|c|c|c|c|c|c|c|c|}
\hline \multirow{3}{*}{ Station } & \multirow{3}{*}{$\begin{array}{c}\text { Period } \\
\text { (number of months) }\end{array}$} & \multicolumn{3}{|c|}{ Wettest condition } & \multicolumn{3}{|c|}{ Driest condition } \\
\hline & & \multirow{2}{*}{ Date of start } & \multicolumn{2}{|c|}{ SPI } & \multirow{2}{*}{ Date of start } & \multicolumn{2}{|c|}{ SPI } \\
\hline & & & Value & Category & & Value & Category \\
\hline \multirow[t]{4}{*}{ Zaouiat Sidi Hamza } & 12 & $2014 / 11$ & 2.74 & EW & $1983 / 12$ & -2.00 & ED \\
\hline & 36 & $2006 / 05$ & 2.09 & EW & $1981 / 11$ & -1.85 & SD \\
\hline & 60 & $2006 / 07$ & 1.70 & SW & $1979 / 11$ & -2.17 & ED \\
\hline & 120 & $2006 / 04$ & 1.59 & SW & $1977 / 02$ & -2.34 & ED \\
\hline \multirow[t]{4}{*}{ M'Zizel } & 12 & $2008 / 01$ & 3.15 & EW & $1981 / 03$ & -2.18 & ED \\
\hline & 36 & $2006 / 05$ & 2.95 & EW & $1998 / 04$ & -1.85 & SD \\
\hline & 60 & $2006 / 07$ & 2.72 & EW & $1997 / 02$ & -1.76 & SD \\
\hline & 120 & $2005 / 11$ & 2.23 & EW & $1976 / 10$ & -1.46 & SD \\
\hline \multirow[t]{4}{*}{ Foum Zaabel } & 12 & $2008 / 02$ & 3.17 & EW & $2000 / 06$ & -1.87 & SD \\
\hline & 36 & $2006 / 01$ & 2.66 & EW & $2000 / 1$ & -2.00 & ED \\
\hline & 60 & $2006 / 01$ & 2.14 & EW & 1996/08 & -1.88 & SD \\
\hline & 120 & $2003 / 06$ & 1.95 & SW & 1996/09 & -1.60 & SD \\
\hline \multirow[t]{4}{*}{ Foum Tillicht } & 12 & $2007 / 12$ & 2.72 & EW & $2012 / 12$ & -2.32 & ED \\
\hline & 36 & $2006 / 04$ & 2.30 & EW & $1982 / 06$ & -1.94 & SD \\
\hline & 60 & $2006 / 01$ & 2.01 & EW & $1982 / 06$ & -2.24 & ED \\
\hline & 120 & $2002 / 02$ & 1.35 & MD & 1978/01 & -2.05 & ED \\
\hline
\end{tabular}

\section{Trend analysis}

Annual rainfall trend analysis over the four stations indicates that there are no significant positive or negative trends. There is a negative tendency in rainfall at Foum
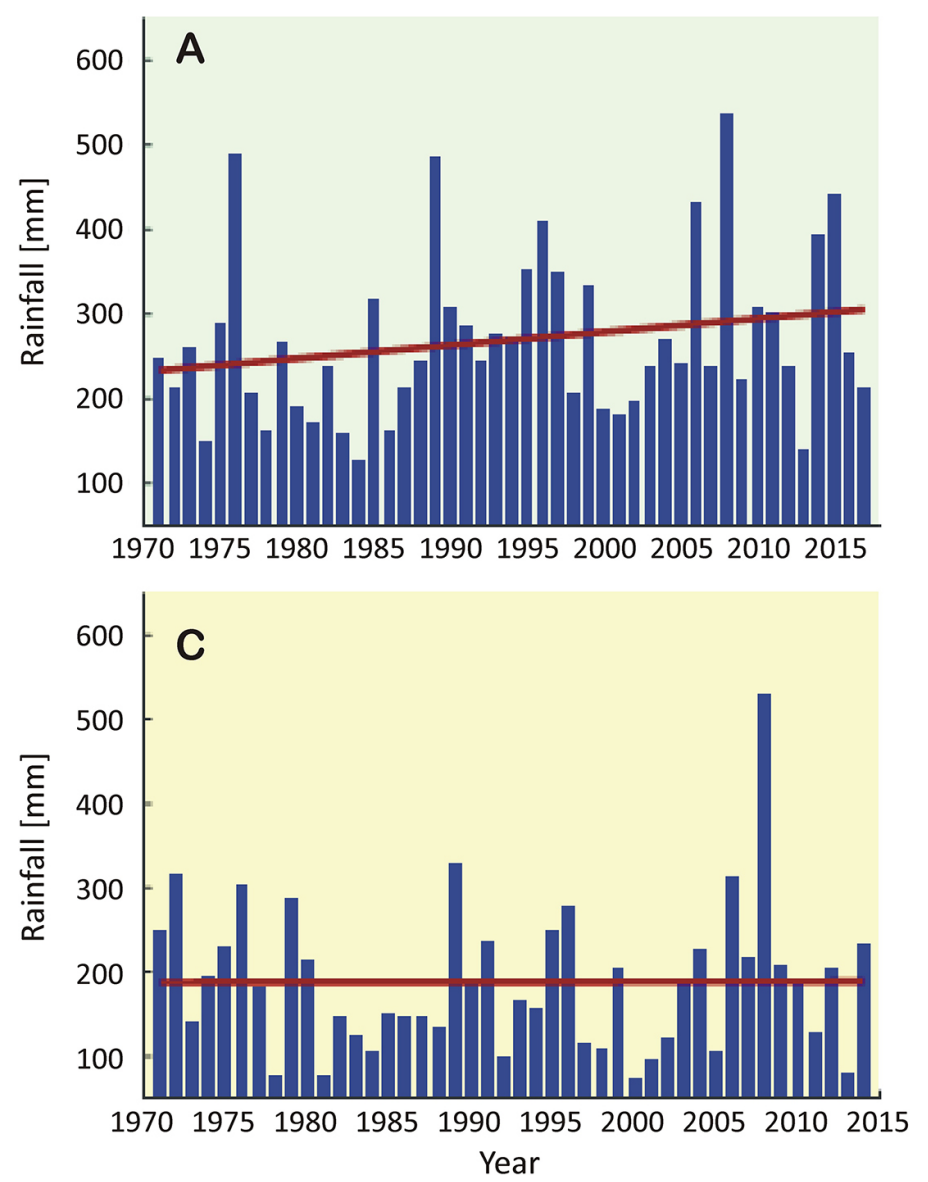

Tillicht and a positive tendency at the Foum Zaabel, Zaouiat Sidi Hamza and M'Zizel stations (Fig. 4).

For overall monthly trends we observed a positive significant trend or tendency in rainfall in $67 \%$
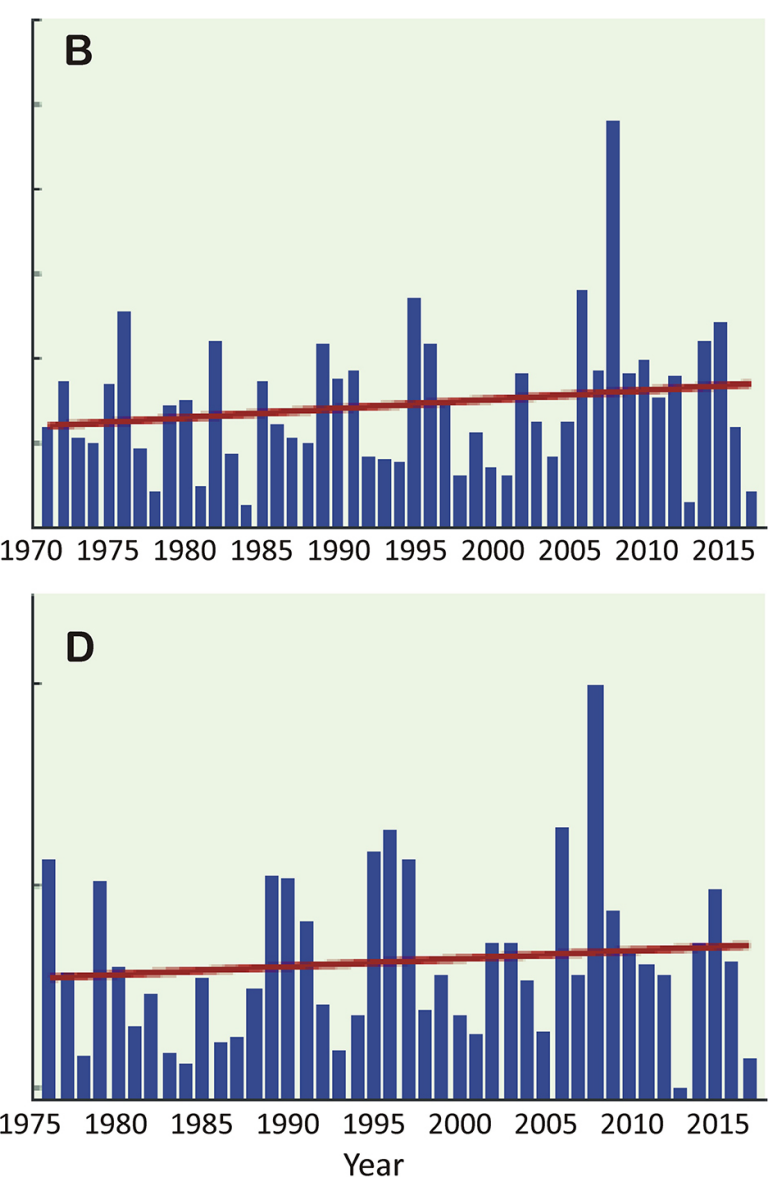

Fig. 4. Annual rainfall trends in the Zaouiat Sidi Hamza (A), M'Zizel (B), Foum Tillicht (C), and Foum Zaabel (D) stations. Light green and yellow backgrounds indicate a positive and negative tendency respectively 
of months (Fig. 5). Monthly trend analysis revealed that $17 \%$ and $8 \%$ of the months displayed a significant positive and negative trend while $50 \%$ and $25 \%$ of the months revealed positive and negative tendencies (Fig. 5). A significant positive trend was observed in August (at all stations), July (at M'Zizel and Foum Zaabel) and March (at Foum Tillicht and M'Zizel) while, a signifi- cant negative trend was observed in April at all stations (Fig. 5). In the other months, trend analysis confirmed no significant trend in monthly rainfall (Fig. 5). There was a positive tendency in September, October and June (at all stations), February (Zaouiat Sidi Hamza, M'Zizel and Foum Zaabel), in November (Zaouiat Sidi Hamza, Foum Tillicht and Foum Zaabel).
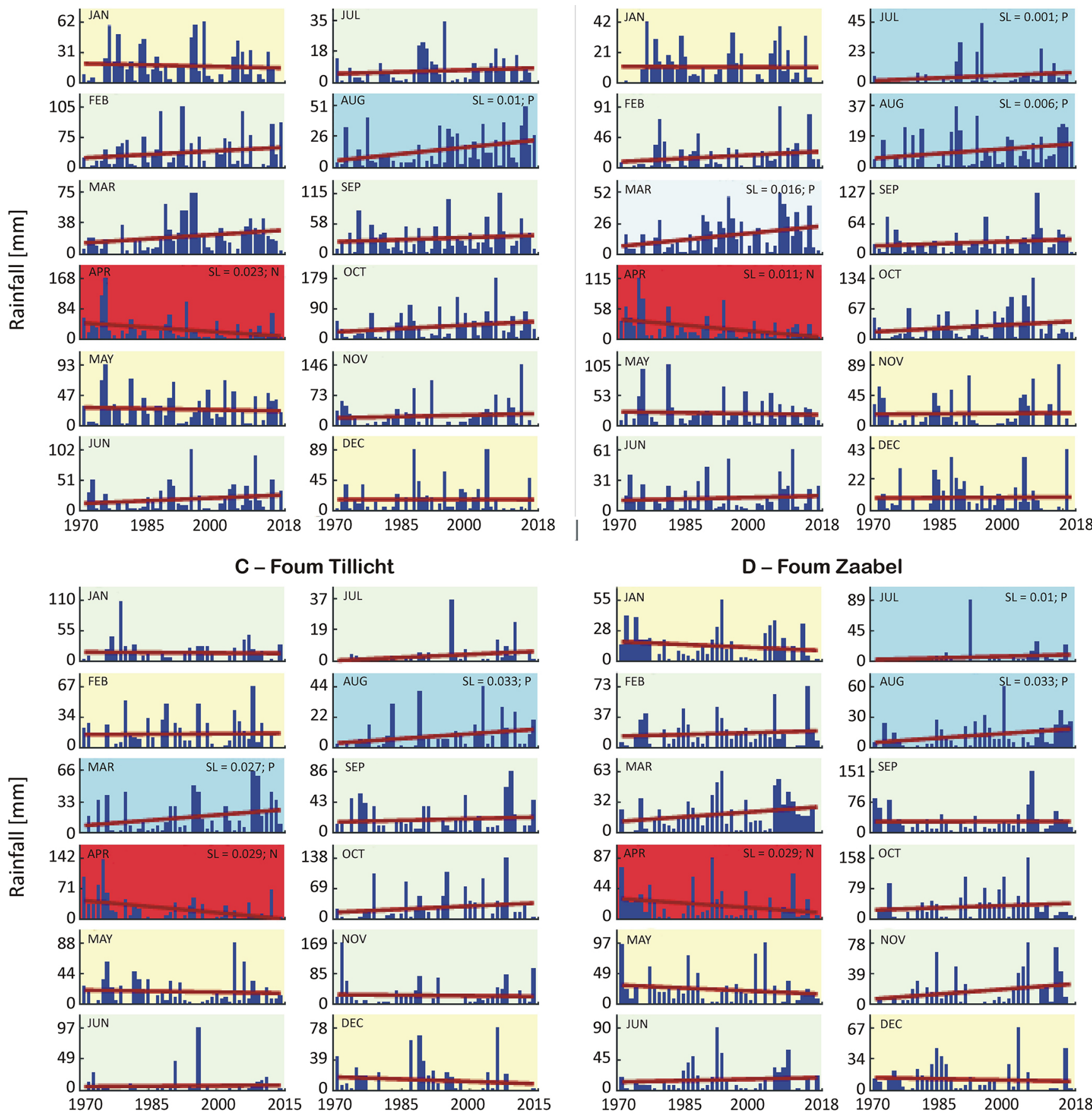

\section{D - Foum Zaabel}
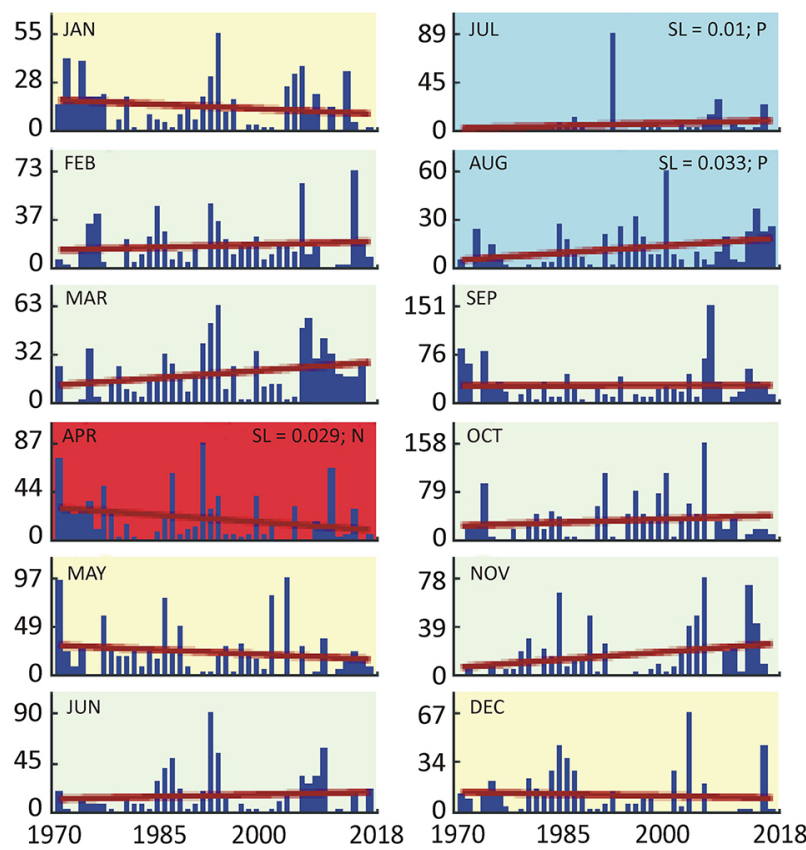

Fig. 5. Monthly rainfall trends in the Zaouiat Sidi Hamza (A), M’Zizel (B), Foum Tillicht (C), and Foum Zaabel (D) stations. Light green and yellow backgrounds indicate a positive and negative tendency respectively, blue and red indicate a positive and negative significant trend, SL denotes a significant level 
Quarterly trend analysis of rainfall shows a positive trend during summer in JJA (June, July and August) for all stations and JAS and ASO at the Zaouiat Sidi Hamza station (Fig. 6). Further, only in AMJ (April, May and June) did we observe negative trend in AMJ at Foum Zaabel (Fig. 6). The rest of quarterly data shows a positive $(50 \%)$ or negative tendency $(35 \%)$.

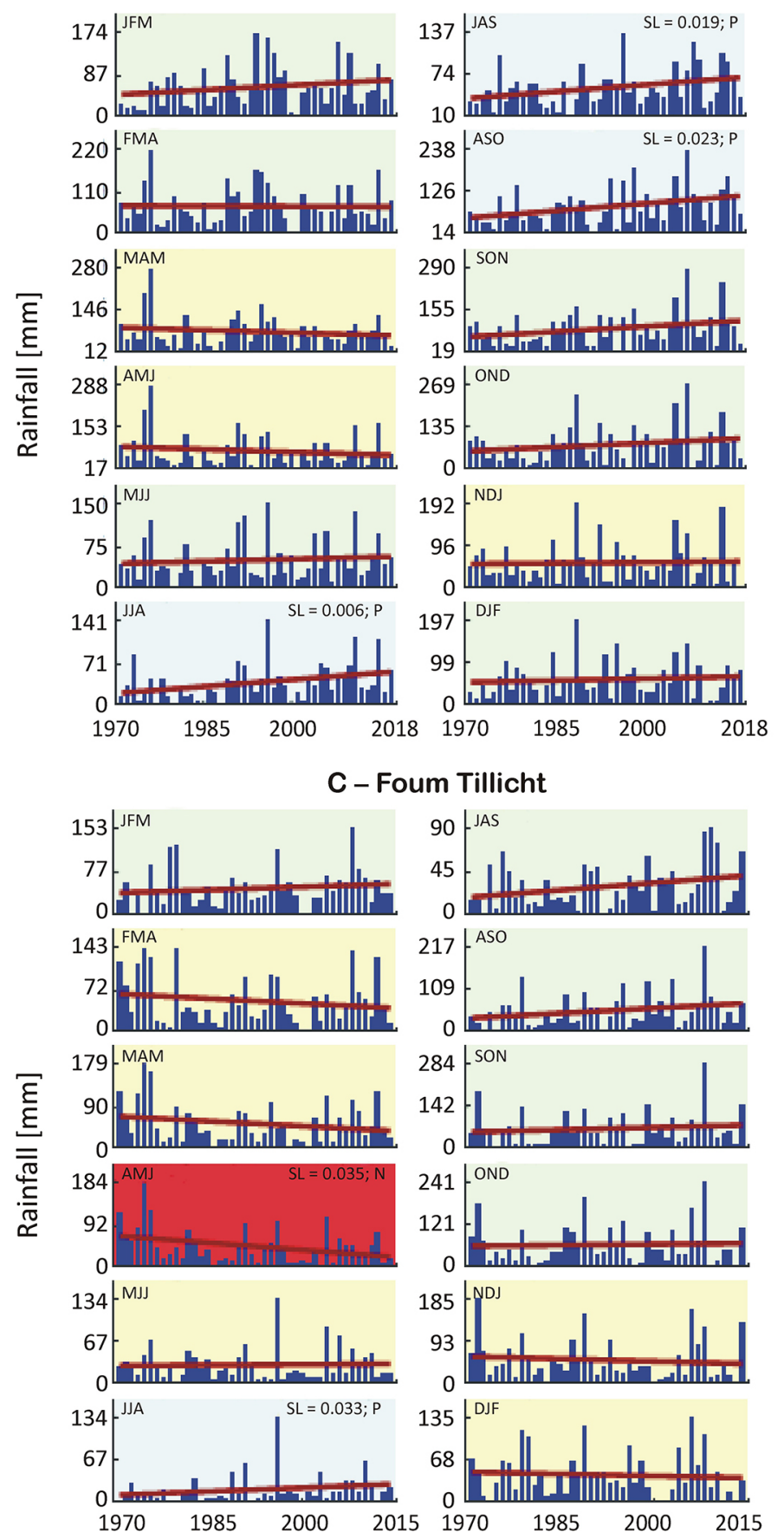

Regarding semesterly rainfall, significant and positive trends were observed during MJJASO (May-October), JJASON (June-November) and JASOND (June-December) at Zaouiat Sidi Hamza, in MJJASO (May-October) and JJASON (June-November) at M'Zizel and JJASON (June-November) at Zaabel (Fig. 7 ). In the other six months of trend analysis, we found a positive (62.5\%) or negative tendency (19\%).
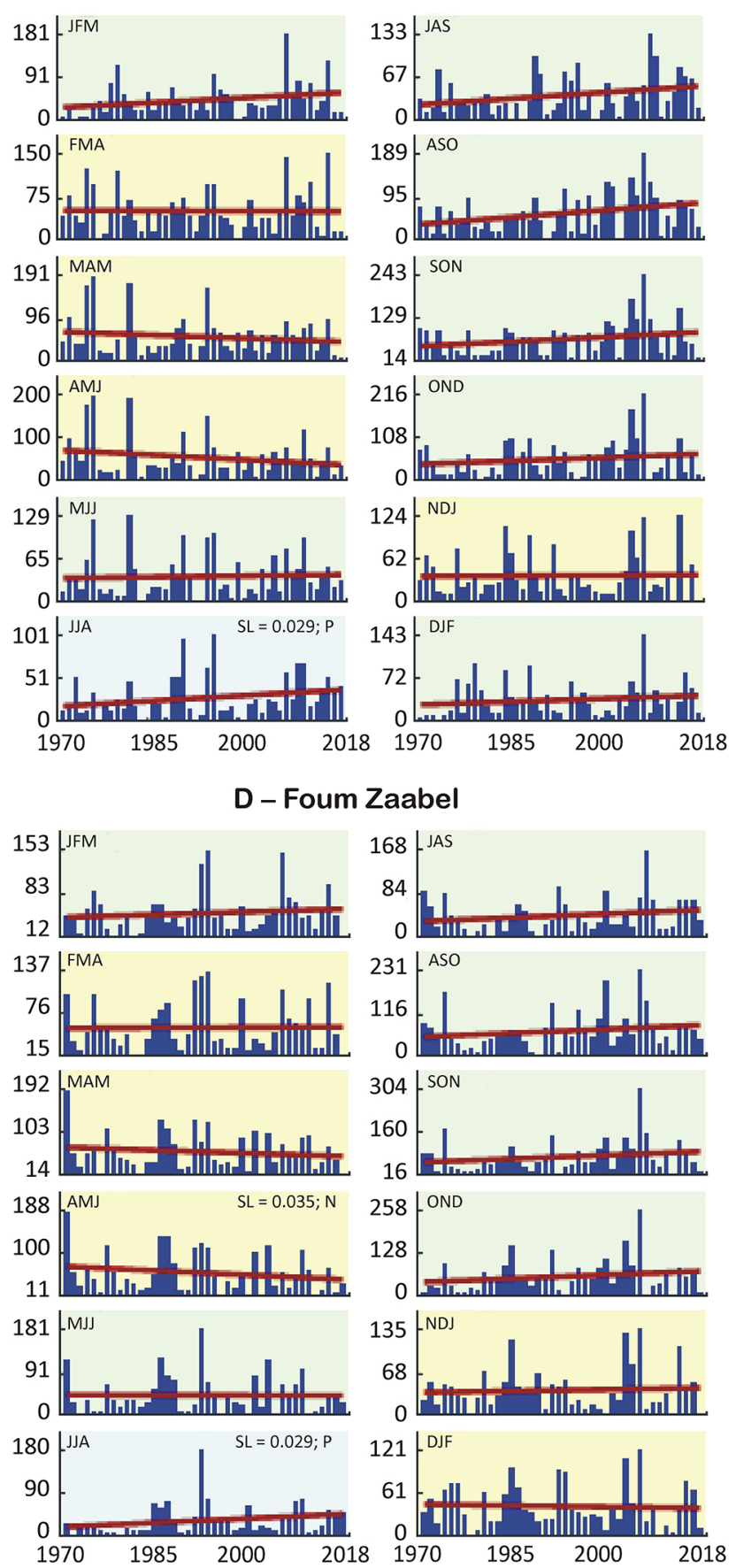

Fig. 6. Quarterly trend analysis of rainfall in the Zaouiat Sidi Hamza (A), M'Zizel (B), Foum Tillicht (C), and Foum Zaabel (D) stations. Light green and yellow backgrounds indicate a positive and negative tendency respectively, blue and red indicate a positive and negative significant trend, SL denotes a significant level 
A - Zaouiat Sidi Hamza
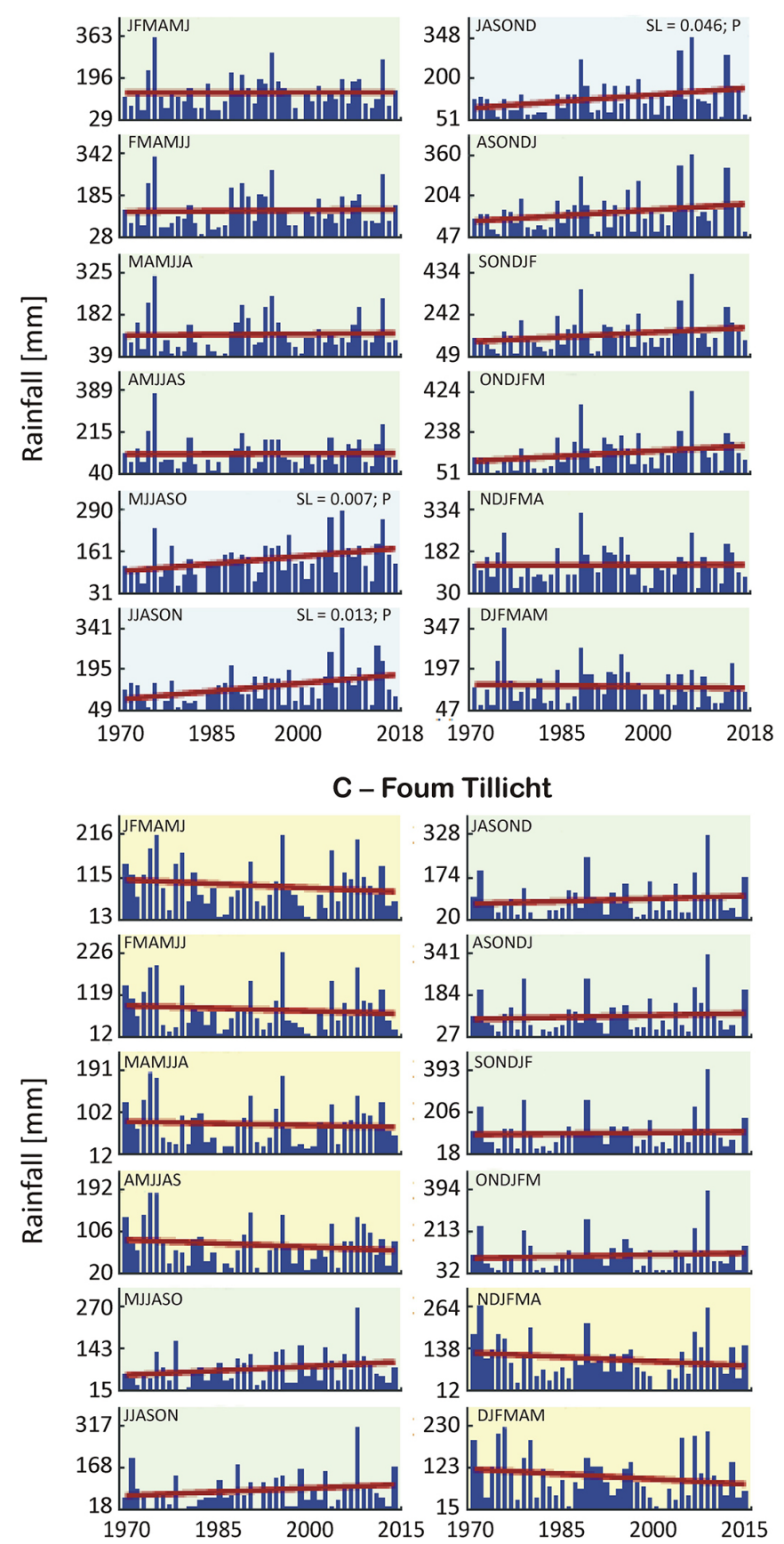

B - M'Zizel

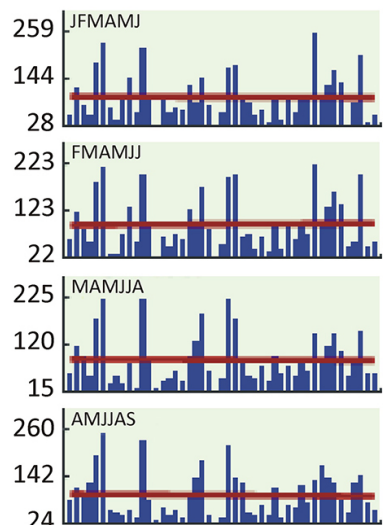

273 JASOND

310 ASONDJ $^{-}$

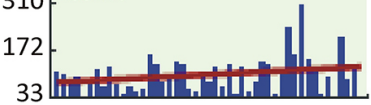

386 - SONDJF

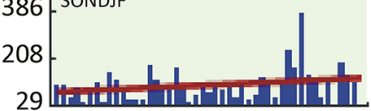

396 - ONDJFM
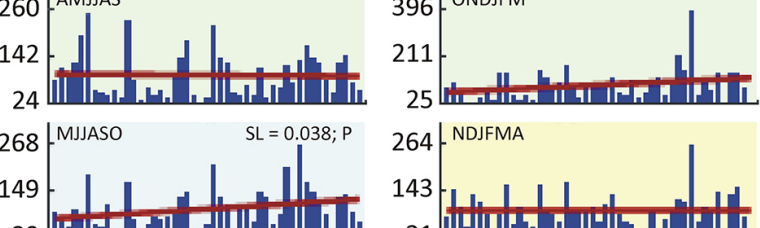

264 - NDJFMA

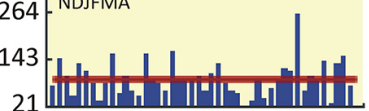

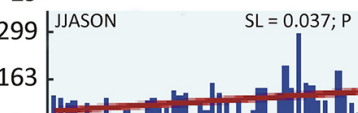

233. DJFMAM

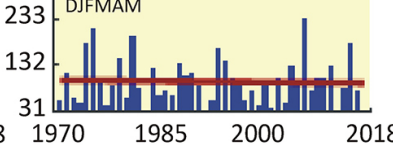

D - Foum Zaabel

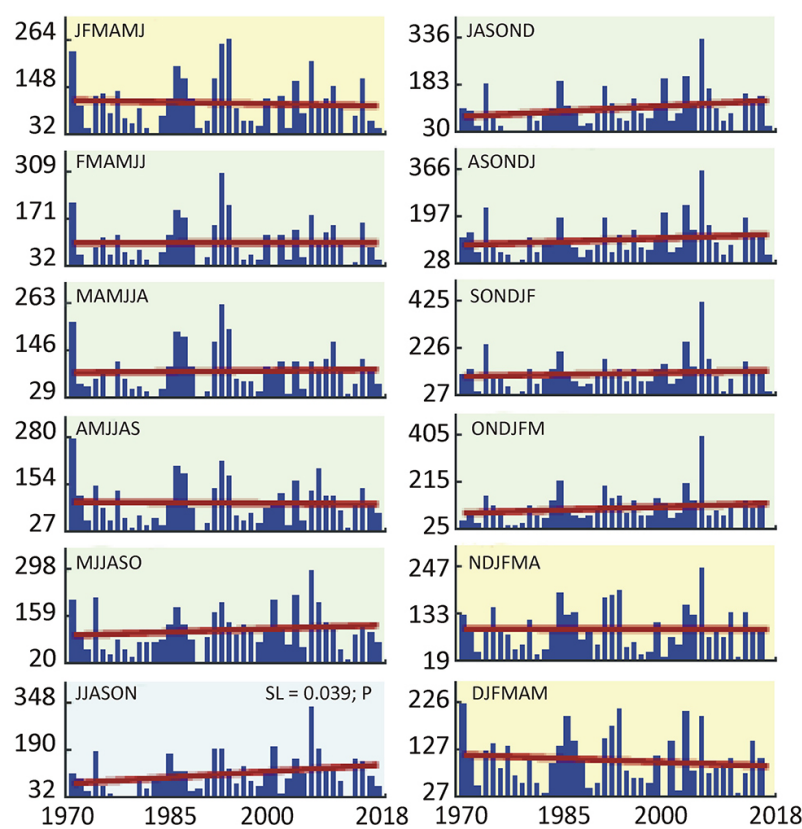

Fig. 7. Semesterly trend analysis of rainfall in the Zaouiat Sidi Hamza (A), M'Zizel (B), Foum Tillicht (C), and Foum Zaabel (D) stations. Light green and yellow backgrounds indicate a positive and negative tendency respectively, blue and red indicate a positive and negative significant trend, SL denotes a significant level

\section{Conclusion}

This paper presents a study to evaluate drought recurrence and rainfall variability using the SPI and Man-Kendall test in different time scales in the High Ziz river Basin, central High Atlas, Morocco. The following conclusions can be drawn from the study; the results of our study revealed that annual rainfall magnitude in Zaouiat Sidi Hamza, M'Zizel and Foum
Zaabel have a positive tendency while in Foum Tillicht we observed a negative tendency. At all stations, the trend was not significant annually. In April and August, the rainfall showed negative and positive trends at all stations. The overall monthly trend indicated in $67 \%$ of months was a positive significant $(17 \%)$ trend or tendency $(50 \%)$ in rainfall. Quarterly trend analysis of rainfall displayed a positive trend during summer in JJA (June, July and August) for all stations, while only 
in Foum Zaabel was a negative trend observed in AMJ (April, May, June).

In general, the calculation of the standardized precipitation index and the obtained results allowed us to establish the sequences of droughts at the four stations of the Ziz basin. The results indicated an alternation of wet and dry sequences: i) Long-term variability of precipitation over the regions showed in contrast to a dry period, which started in the late nineteen seventies, a wet period observed from the late nineteen nineties; ii) Maximum SPI and the wettest periods were recorded after 2002, iii) for Foum Zaabel, the driest decade began 1996 while for the other stations the driest period commenced in around 1977.

\section{Acknowledgement}

The authors thank Mr. H. Amar and Mr. T. Bahaj for their valuable assistance.

\section{References}

Ashraf F.B., Haghighi A.T., Riml J., Alfredsen K., Koskela J.J., Kløve B., Marttila H., 2018, Changes in short term river flow regulation and hydropeaking in Nordic rivers, Sci. Rep. 8(1): 17232.

Burton I., Kates R.W., White G., 1978, The environment as hazard., Oxford University Press, New York, 240 pp.

Dai A., Trenberth K.E., Qian T., 2004, A global dataset of Palmer Drought Severity Index for 1870-2002: Relationship with soil moisture and effects of surface warming, J. Hydrometeorol. 5(6): 1117-1130.

Darabi H., Choubin B., Rahmati O., Haghighi A.T., Pradhan B., Kløve B., 2019, Urban flood risk mapping using the GARP and QUEST models: A comparative study of machine learning techniques, J. Hydrol. 569: 142-154.

Darabi H., Torabi Haghighi A., Fazel N., Klöve B., 2017, A scenario based approach to separate the impacts of land use and climate alteration on daily flow regime indices [Abstract], EGU General Assembly Conference Abstracts Vol. 19, Viena: 7291.

Gilbert R.O., 1987, Statistical methods for environmental pollution monitoring, Van Nostrand Reinhold Company Inc., New York, 320 pp.

Haghighi A.T., Sonmez M.E., Fazel N., Kløve B., 2018, Relations between land use changes and drought in Kavar Depression (Iran), KSU J. Agric. Nat. 21(3): 397-406.

Homdee T., Pongput K., Kanae S., 2016, A comparative performance analysis of three standardized climatic drought indices in the Chi River basin, Thailand, Agric. Nat. Res. (ANRES) 50(3): 211-219.

Huang S., Huang Q., Chang J., Leng G., Xing L., 2015, The response of agricultural drought to meteorological drought and the influencing factors: a case study in the Wei River Basin, China, Agric. Water Manage. 159 : 45-54.

Igmoullan B., Sadki D., Fedan B., Chellai E.H., 2001, Evolution géodynamique du Haut-Atlas de Midelt (Maroc) pendant le Jurassique: UN exemple d'interaction entre la tectonique et l'eustatisme (Geodynamic evolution of the atlas mountain (southern Midelt, Morocco) at the LiasDogger transition: an example of the interaction between tectonic and eustatism), Bulletin de l'Institut Scientifique, Section Sciences de la Terre 23 : 47-54 (in French, English summary).

[IPCC] Intergovernmental Panel on Climate Change, 2000, Special report on emissions scenarios (SRES). A special report of Working Group III of the Intergovernmental Panel on Climate Change, Cambridge University Press, Cambridge, $595 \mathrm{pp}$.

[IPCC] Intergovernmental Panel on Climate Change, 2007, Climat Change 2007: The physical science basis. Contribution of Working Group I to the Fourth Assessment Report of the IPCC, Cambridge University Press, Cambridge, $1009 \mathrm{pp}$.

Kendall M.G., 1948, Rank correlation methods, Griffin, London, $160 \mathrm{pp}$.

Lin Y.P., Hong N.M., Wu P.J., Wu C.F., Verburg P.H., 2007, Impacts of land use change scenarios on hydrology and land use patterns in the $\mathrm{Wu}-\mathrm{Tu}$ watershed in Northern Taiwan, Landsc. Urban Plan. 80(1-2): 111-126.

Lloyd-Hughes B., Saunders M.A., 2002, A drought climatology for Europe, Int. J. Climatol. 22(13): 1571-1592.

Mann H.B., 1945, Nonparametric tests against trend, Econometrica 13(3): 245-259.

McKee T.B., Doesken N.J., Kleist J., 1993, The relationship of drought frequency and duration to time scales, Proc. of the 8th Conference on Applied Climatology, American Meteorological Society Anaheim: 179-183.

Mishra A.K., Singh V.P., 2010, A review of drought concepts, J. Hydrol. 391(1-2): 202-216.

Oliveira-Júnior J.F., Gois G., Terassi P.M.B., Silva Junior C.A., Blanco C.J.C., Sobral B.S., Gasparini K.A.C., 2018, Drought severity based on the SPI index and its relation to the ENSO and PDO climatic variability modes in the regions North and Northwest of the State of Rio de Janeiro - Brazil, Atmos. Res. 212: 91-105.

Oloruntade A.J., Mohammad T.A., Ghazali A.H., Wayayok A., 2017, Analysis of meteorological and hydrological droughts in the Niger-South Basin, Nigeria, Glob. Planet. Chang. 155: 225-233.

Pirnia A., Golshan M., Darabi H., Adamowski J., Rozbeh S., 2018, Using the Mann-Kendall test and double mass curve method to explore stream flow changes in response to climate and human activities, J. water Clim. Chnge 162: 1-18.

Stagge J.H., Kohn I., Tallaksen L.M., Stahl K., 2015, Modeling drought impact occurrence based on meteorological drought indices in Europe, J. Hydrol. 530: 37-50.

Thom H.C.S., 1966, Some methods of climatological analysis, WMO Technical Note 81, Secretariat of the World Meteorological Organization, Geneva, $53 \mathrm{pp}$.

Vicente-Serrano S.M., López-Moreno J.I., 2005, Hydrological response to different time scales of climatological drought: an evaluation of the Standardized Precipitation Index in a mountainous Mediterranean basin, Hydrol. Earth Syst. Sci. 9(5): 523-533. 